\title{
TIEMPOS DE MARIPOSAS Y RUISEÑORES: UNA REFLEXIÓN SOBRE EL TRABAJO SOCIAL EN LA REPARACIÓN A VÍCTIMAS DEL CONFLicto ARMADO EN COLOMBIA
}

\author{
TIME OF BUTTERFLIES AND NIGHTINGALES: \\ REFLECTION ON SOCIAL WORK IN REPARATION FOR \\ THE VICTIMS OF THE ARMED CONFLICT IN COLOMBIA
}

jadora Social Uni-

dad de Cartage-

Ha trabajado en

ción psicosocial a

mas del conflicto

do con la Pasto-

ocial de Cartagena

la construcción

lemoria histórica

a Secretaria de las

mas y Derechos

anos de Bolívar

vez trabajó en ur.

ecto de educación

la paz a través del

con jóvenes en la

ación Mi sangre.

almente adelanta

lios de maestría en

pología en la Fa

Latinoamericana encias Sociales.

\author{
Por: Laura Martínez Salcedo
}

Recibido: 4 de agosto de 2014 - Aprobado: 2 de abril de 2015

\begin{abstract}
RESUMEN
Este artículo pretende generar un análisis reflexivo desde una práctica realizada a través de un ejercicio investigativo en la Secretaría de Víctimas y Derechos Humanos del departamento de Bolívar, fundamentada teórica, metodológica, ética y políticamente, como una ampliación del espectro de la intervención desde el trabajo social con víctimas del conflicto armado en la reparación integral y especialmente, en la dimensión simbólica de esta. No pretenderá por tanto, ser un modelo de intervención, sino una reflexión en sí misma. Contiene generalidades del conflicto armado en Colombia, el contexto de este en el departamento de Bolívar y sus víctimas, ¿quiénes son estas?, ¿cómo las nombra le ley el trabajo social?. En cuanto a la intervención de trabajo social, aborda la ley 1448, un bosquejo general de la política pública departamental para víctimas, la asistencia en dicha reparación y unas recomendaciones para el ejercicio de la profesión en este contexto. Por último, menciona y propone el arte como una herramienta de intervención, no en búsqueda de la belleza en sí misma, sino en el deseo de reparar el interior de las personas, y a su vez, formar y educar a partir de la construcción de una nueva historia contada desde las víctimas.
\end{abstract}

Palabras claves: Conflicto armado, víctimas, reparación integral, reparación simbólica, trabajo social.

\begin{abstract}
This article expects to generate a thoughtful analysis done by a research practice at the Victims' Rights are Human Rights Secretary of Bolivar, based on theoretical, methodological, ethical and political fundaments, as an extension of the spectrum of intervention from social work with victims of armed conflict in an integral reparation, especially in the symbolic dimension of this. It does not pretend therefore be an intervention model, but a reflection itself. Contains basic concepts of the armed conflict in Colombia, the context of this in the department of Bolivar and its victims, who are they? Who are the victims fro a social wor'ks point of view?. As for social work intervention, a general outline of the departmental public policy for victims, assistance in such reparation and recommendations for the practice of the profession in this context, it's been addressed by the law 1448. Finally, mention and proposes art as an intervention tool, not in pursuit of beauty in itself, but both in the desire to repair the inside of people, and to train and educate from a new story told from the victims.
\end{abstract}

Keywords: Armed conflict, victims, integral reparation, symbolic reparation, social work. 


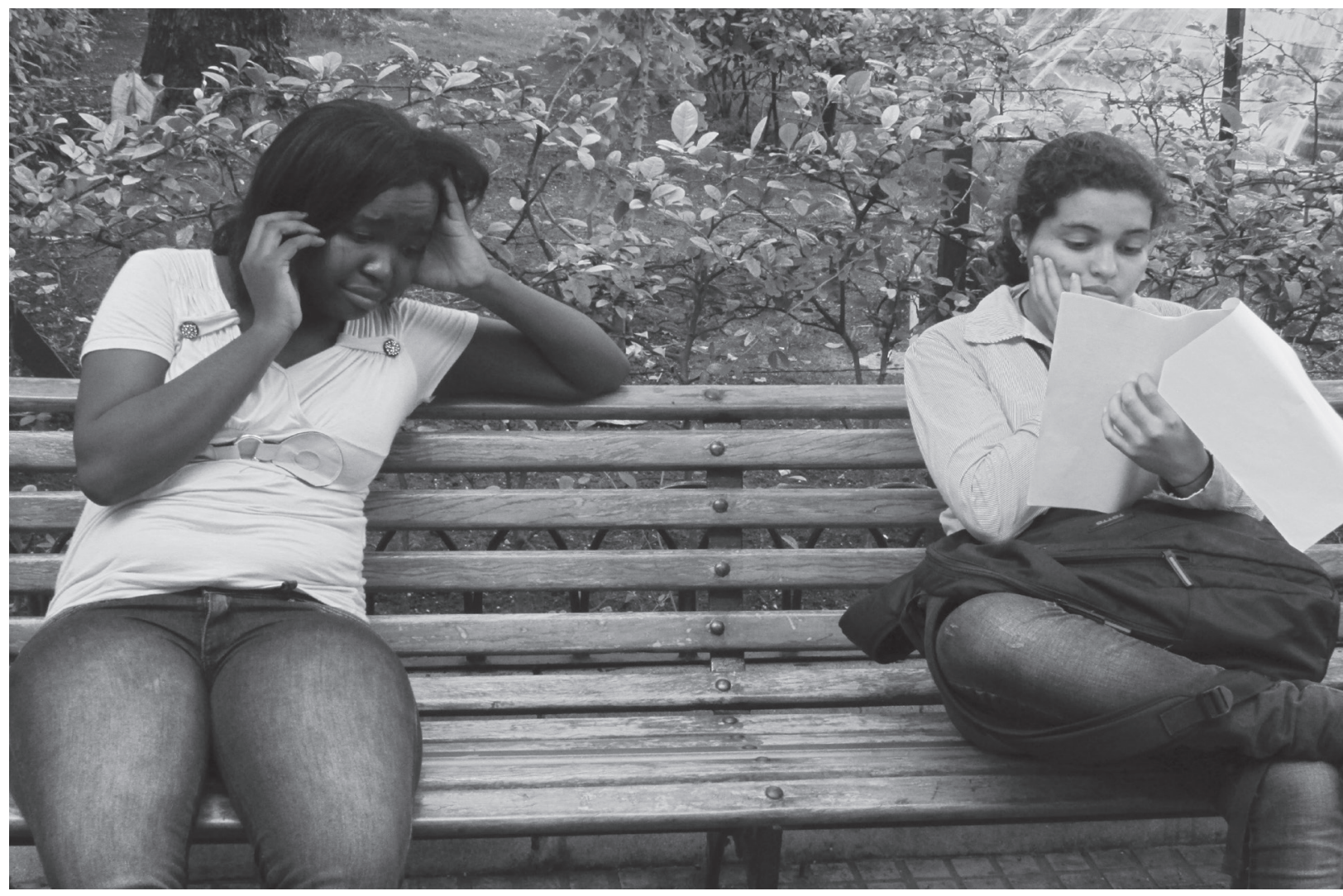

Foto: Clara Mercado B

\section{Introducción}

E

l siguiente artículo cuyo objetivo principal es generar una reflexión sobre el papel del trabajo social en la reparación integral y de manera especial, en su dimensión simbólica, a víctimas del conflicto armado en el departamento de Bolívar, surge en un proceso de prácticas sociales investigativas y reflexivas en la Secretaría de Víctimas y Derechos Humanos de la gobernación del mismo departamento durante el período del 20132014, luego de la creación de este despacho como instancia articuladora de la Ley de Víctimas en el territorio bolivarense en el año 2012. Toma en parte como referente el diseño y ejecución del proyecto "Divulgación de hechos victimizantes colectivos en Bolívar".

Este ejercicio de pensarse el papel de trabajo social en un escenario de conflicto armado cuando apenas se da el surgimiento de esta secretaría, genera grandes desafíos y se convierte en una tarea necesaria para el enriquecimiento de la profesión, y además, para la construcción de procesos de paz y de reconciliación en el territorio, que pueden empezar por la reparación integral a las víctimas, dotando a éstas de voces múltiples y del protagonismo necesario para la transformación social, más allá del asistencialismo soterrado ${ }^{1}$ que les lleva a la pasividad y más allá de los diálogos de paz fuera del territorio nacional.

1 El asistencial
según Norberto A
(1980), ha sido la
cia histórica de la
fesión, siendo ur
las actividades so
que casi como un
tumbre han imple
tado principalmen
clases dominantes
menguar de m
mínima la miseri
generan al manter
status quo y par
petuar el sistema
plotación. La esen
asistencialismo,
Alayón, es dar
que alivie, relativi
problemáticas, d
forma que garan
preservar los privi
de unos pocos. No. 15. Agosto de 2015 Palobra 
Se hará mención por lo tanto, de conflicto y no de "postconflicto", comprendiendo a Jean Paul Lederach (citado en Conforti, 2003), experto en mediación y análisis de conflictos que, por haberse firmado un acuerdo de paz en cualquier país, se debería hablar de postacuerdo. Y es así, como se ha venido entendiendo desde este ejercicio práctico y reflexivo, que los conflictos no cesan sino que se transforman, así como se transforman las formas de abordarlos, intervenirlos y dinamizarlos.

Es casi una obligación -si se quiere tener una intervención fundamentada- que la teoría anteceda a la actuación y luego vuelva a precederla, como un proceso de reflexión-acción-reflexión. De hecho, Nora Aquín (citado en Cifuentes, 2004) ha precisado que no basta actuar para entender. La intervención, si no está respaldada por una teoría que dé cuenta de ella, se mueve a ciegas, inconsciente de los efectos que produce, incapaz de reconocer límites y abrir posibilidades, inhabilitada para la crítica y el perfeccionamiento, condenada, si se quiere, a ser copia de sí misma. Es decir, sin una reflexión teórica previa y posterior a la actuación en la reparación a víctimas del conflicto armado, sobre cuestiones propias de esta intervención social, no sería posible una intervención contextualizada y fundamentada como la que se plantea en este espacio.

Sobre el conflicto, por una parte, entre las teorías sociológicas conflictualistas se pueden encontrar dos grandes corrientes: la marxista y la liberal. Ralf Dahrendorf plantea que, la primera comprende la causa del conflicto en una lucha de clases sociales, pero para la segunda -aunque cree que las sociedades pueden estar organizadas en clases sociales-, esta categoría no le es suficiente. La corriente liberal emplea la categoría de grupo social para identificar las partes participantes del conflicto (Citado en Silva, 2008). Por ejemplo, en Colombia la violencia bipartidista permitió que fueran dos los grupos envueltos en ella (liberales y conservadores) que, pertenecientes a la misma clase social mantuvieron su disputa por décadas y esta situación conllevó a guerras civiles, nacionales y en las regiones. Es decir, no podría explicarse el conflicto en Colombia como un asunto solamente de clases sociales.

Por otro lado, el conflicto interno también puede entenderse a partir de dos corrientes que se centran en el papel que desempeñan las variables económicas. La primera está ligada al resentimiento, la injusticia, desigualdad, la exclusión y discriminación; es decir, "el potencial para la violencia colectiva varía sustancialmente con la intensidad y el alcance de la privación relativa entre los miembros de una colectividad" (Gurr, 1970, p. 24). La segunda está basada en la codicia que, aumenta en la medida que existen algunos incentivos financieros para apalancar la rebelión. 
Muchas otras teorías vendrán a considerar el resentimiento como factor decisivo en el conflicto que se vive en el país, pero aunado a la pésima administración de los recursos, su inequitativa repartición y las políticas estatales que han impedido históricamente que muchos sectores se beneficien de estas riquezas. En Colombia es muy importante nombrar la lucha por la tierra -su instrumentalización- como factor primordial en el desarrollo del conflicto armado, acabando con los territorios social, cultural, política y económicamente construidos.

Lo que la historia ha ido develando con relación a las víctimas de este conflicto es que, estas han sido en su mayoría poblaciones empobrecidas, pueblos afrocolombianos e indígenas, opositores y disidentes, y de manera particular, el conflicto armado ha recaído sobre las mujeres, los niños y niñas (Grupo de Memoria Histórica, 2013, p.25). En Colombia ya se registran oficialmente casi siete millones de víctimas por esta causa.

El conflicto armado en Colombia podría analizarse en tres momentos históricos que coexisten: Según Saúl Franco (2003), el primero tiene que ver con el problema narco, es decir, con la producción, procesamiento, circulación y consumo de sustancias psicoactivas y adictivas consideradas ilegales. El segundo obedece al conflicto político-militar, que implicó en un comienzo a las guerrillas y a las fuerzas armadas estatales y posteriormente a las organizaciones paramilitares y al conjunto de la denominada sociedad civil. El tercer momento está relacionado con el desarrollo y la consolidación de un modelo económico y de concepción del Estado y de la sociedad sintética y globalmente, el modelo neoliberal.

En cuanto a efectos del conflicto armado, se pueden destacar el desplazamiento forzado, homicidios, secuestros, narcotráfico, analfabetismo, gobernabilidad viciada, repetición del círculo de la pobreza con más fuerza, violencia de género, discriminación, destrucción de tejidos sociales, inseguridad, desapariciones forzadas, pérdida de fuente de trabajo rural, un campo cada vez con menos posibilidades de desarrollo, menos inversión en la cuestión social, e incluso se podría llegar a decir que las consecuencias son incalculables

Aunque el conflicto armado persiste en el tiempo con algunas variaciones, aparece en el escenario nacional la intencionalidad del Estado por reparar de manera integral a las víctimas, y por lo tanto, surge un escenario de intervención profesional para el Trabajo Social. Dicho escenario genera una serie de desafíos y se convierte en una tarea necesaria para el enriquecimiento de la profesión. 
Es por esto que, esta apuesta ético-política implica comprender que la intervención no viene como una demanda de consumidores de productos. Sino que viene exigida y alimentada por personas, por comunidades de personas, por sujetos de derechos que han sido violentados (Aguayo, López \& Quiroz, 2014). Implica poder mirar a los ojos a las víctimas (de manera horizontal) y no como un expediente, un número, una cifra o una estadística más de la violencia en el país, ni mucho menos como una categoría absoluta que abarca todo un universo.

El conflicto armado y sus consecuencias exigen una interpretación más allá de la historia presentada en las escuelas y los libros tradicionales. Por lo tanto, queda en entredicho aquella disyuntiva entro lo que es "real" y lo que es "simbólico". Ambos asuntos se encuentran enlazados en el mundo con el que el trabajo social trata (D’Agostini, 2000). Y es la hermenéutica la que ha permitido que desde el lenguaje surjan probabilidades de nuevas transformaciones, en el que el trabajo social sea terapéutico y emancipador (Adams, Dominelli \& Payne, 2002). Se ha comprendido que las identidades de las víctimas emanan de las categorías con que se nombran desde la intervención social, puesto que la palabra tiene posibilidad de apertura a posibilidades y de cierre por estigmatizaciones. La forma en que se nombran los sujetos y sus realidades han de derivarse de la postura política asumida. La comprensión del lenguaje hablado y no hablado, por lo tanto, se vuelve un campo imprescindible de recolección de información para la intervención; es el campo de batalla en el que se disputa el significado, por lo tanto la lógica estigmatizadora es también una reiteración de violencia (Petautschnig, 2010).

Esta investigación se configura a partir de la utilización de unas técnicas empleadas para la recolección de los datos, de registro y de análisis. Así de esa forma, se optó por una intervención basada en la investigación documental -sobre hechos victimizantes ocasionados para afectar colectividades pero que recayeron sobre algún liderazgo-, desde una revisión sistemática de fuentes secundarias sobre categorías como el contexto del departamento y dinámicas del conflicto dentro de este, las víctimas y la reparación integral, como la realizada a través de la archivística (puntualmente en el periódico El Universal, teniendo como criterio de inclusión la fecha establecida por la ley 1448 parar nombrar una víctima: desde 1985), y sustentada también desde una modalidad de forma dialógica e interactiva, que incluye como técnica para la recolección de información, el diálogo conducido a manera de entrevistas semiestructuradas -algunas fueron más de corte conversacional y 
sin estructurar- con cada comunidad visitada, con cada víctima interactuada, con cada familiar de la víctima, con cada amigo de la víctima; además la observación participante y el análisis de documentos.

La observación participante junto a la entrevista conversacional -también la semiestructurada, algunas grabadas a través de cámaras- ha permitido una interacción con las personas con que se trabaja (las víctimas), generando la posibilidad de escuchar las polifonías de estas, y en sus propias palabras las narraciones a través de las cuales expresa sus conocimientos, sus actitudes, sus prácticas sociales, sus historias personales y colectivas que en el caso del conflicto se vuelven casi una marca, sus situaciones de vida, sueños, frustraciones hacia los demás y hacia sí mismos, las exclusiones, opresiones, inequidades, vulneraciones a las que han sido sometidos, pero también sus fortalezas, sus potencialidades, esperanzas de un mejor futuro -que por lo general tienen que ver con la paz, a veces con el retorno, el progreso de los pueblos, etc.- y sus debilidades (Bonilla y Rodríguez, 1997). Esta forma de interaccionar con las víctimas, las comunidades, los colectivos u organizaciones, ha facilitado un ambiente de confianza o por lo menos de cercanía, porque debido al rezago del Estado se hace difícil volver a confiar en las instituciones estatales y por supuesto, en quienes la representan, pero esa brecha suele irse rompiendo además con el cumplimiento de la labor misional de la secretaría que, al estar recién creada, abre la posibilidad de la novedad.

La observación participante con un análisis posterior, incluso ha permitido interpretar silencios, lágrimas, gestos, vestuarios, manifestaciones culturales, las tensiones que viven y las formas como se da la sociabilidad. Se desarrolló además un análisis anterior a la observación participante y a las interacciones dialógicas, porque de manera especial, para hacer investigación dentro de los territorios en donde se ha desarrollado el conflicto armado se amerita una revisión previa de los documentos que cuentan lo ocurrido -a veces en lenguajes oficiales-, de los espacios geográficos, de las relaciones socioculturales, de los escenarios económicos y políticos, de las intervenciones que se han realizado previamente, para poder tener herramientas de conocimiento en el momento del acercamiento a las víctimas y sus comunidades.

La utilización de una técnica u otra no fue un tema de azar, obedece al contexto, el momento que se vive en los territorios bolivarenses, las tensiones en torno al orden público, el avance o retraso de los procesos de la reparación, los cumplimientos o incumplimientos por parte de las instituciones, entre otras causas y, el respeto por estas. 
Tal como se mencionó, primeramente se realizó una revisión documental sobre hechos victimizantes sucedidos en Bolívar desde el año 1985 hasta el 2011, cuyo rastreo se realizó en distintos portales en la web que estuvieran asociados con la temática objetivo (hechos victimizantes sobre liderazgos con afectaciones colectivas), portales como Verdad abierta, Revista Semana, los periódicos El Espectador, El Tiempo, y El Universal de Cartagena.

Paralelo a esta revisión se procedió a una serie de visitas de campo a algunos de los sujetos con afectaciones colectivas como la Alta Montaña de El Carmen de Bolívar, El Salado, Palenque y la Asociación de Campesinos de Buenos Aires ASOCAB (Comunidad de Las Pavas). A partir de estas cuatro visitas, se reconocieron algunos casos que podrían ser relevantes para la investigación. Sin embargo, fue al finalizar la revisión documental, cuando se eligieron la totalidad de los casos que, al final fueron quince, en todo el territorio pero diferentes en comunidades: Central Unitaria de Trabajadores de Colombia, Unión Sindical Obrera, Universidad de Cartagena, el municipio de San Jacinto, las veredas Guamito, Macayepo, Lázaro, Ojo Seco y el corregimiento El Salado en El Carmen de Bolívar, Magangué, Pastoral Social de la diócesis de Magangué, Barranco de Loba, Simití y Norosí.

Esta construcción de memoria alrededor de estas afectaciones colectivas se produce precisamente previendo que el desconocimiento de dinámicas del conflicto armado en el país y específicamente en el departamento de Bolívar por parte de la población civil, no permite una sólida reprobación social del conflicto, garantías de no repetición desde una ciudadanía activa, derecho a la verdad y divulgación de los hechos que han victimizado a casi 600.000 personas en el territorio bolivarense.

\section{El conflicto armado en Bolívar}

e manera más específica, en el departamento bolivarense debido a que posee escenarios como los Montes de María al norte, la Serranía de San Lucas hacia el centro y el sur de Bolívar, se encuentra ubicado en un punto estratégico del país que lo convierte en un escenario de conquistas. En comparación con otros departamentos de la Región Caribe, Bolívar supera de manera considerable a sus pares regionales. En el departamento han declarado sus hechos y fueron incluidas 22.895 personas como víctimas de situaciones diferentes al desplazamiento forzado, de estas personas, 15.924 corresponden a homicidios, 2.310 a casos de desaparición forzada, las lesiones personales tienen una participación con 1.835 víctimas, hay reportados 751 secuestros, delitos contra la libertad e integridad sexual 97 y víctimas de reclutamiento forzado a menores 163 casos (UARIV, 2014). 
Al mismo tiempo, el departamento registra el 23.9\% de casos de abandono forzoso de sus tierras en la región, luego sigue el Cesar con 15.2\% y Magdalena con el 10\%. En términos de hechos de un mayor impacto, podemos encontrar la subregión de Montes de María que registra al menos 56 masacres en las últimas tres décadas, solo superado por la zona de la Sierra Nevada de Santa Marta (Comisión Nacional de Reparación y Reconciliación, 2010).

En las últimas tres décadas, el territorio bolivarense ha sido violentado por la totalidad de actores armados que han intervenido en el conflicto interno, las guerrillas de CRS, PRT, FARC, ELN, EPL, los paramilitares, y la Fuerza Pública (Ejército, Armada y Policía), sostuvieron enfrentamientos y actos contra la población civil en este período. Fue así como el territorio cambió de "poseedores", "leyes" y actores. Mientras un grupo al margen de la ley dominaba, las personas de alguna u otra manera aprendían a convivir con dicho grupo, pero el punto álgido del conflicto armado en la zona eran las disputas por el poder entre los diferentes bandos (Gallego, comunicación personal, 3 de octubre del 2014).

\section{¿Quiénes son las víctimas del conflicto armado?}

T a Ley de Víctimas y Restitución de Tierras 1448 del 2011, sentó las bases para implementar la política pública para la atención y reparación integral, bajo los principios de progresividad, gradualidad y sostenibilidad. De la misma manera, establece la institucionalidad encargada para que esta se implemente (Unidad para la Atención Y Reparación Integral a las Víctimas, UARIV), crea el Sistema Nacional de Atención y Reparación Integral a las Víctimas -SNARIV- dentro del cual las entidades del orden nacional y territorial, tienen la responsabilidad de formular, implementar y monitorear dicha política. También creo el Centro Nacional de Memoria Histórica cuyo objetivo es reunir y recuperar todo el material documental y testimonial de los hechos que conllevaron a las violaciones de los derechos de las víctimas.

Esta Ley estipula en su artículo 3 que: "Se consideran víctimas, para los efectos de esta Ley, aquellas personas que individual o colectivamente hayan sufrido un daño por hechos ocurridos a partir del $1^{\circ}$ de enero de 1985 , como consecuencia de infracciones al Derecho Internacional Humanitario o de violaciones graves y manifiestas a las normas internacionales de Derechos Humanos, ocurridas con ocasión del conflicto armado interno.

También son víctimas el cónyuge, compañero o compañera permanente, parejas del mismo sexo y familiar en primer grado de consanguinidad, primero 
civil de la víctima directa, cuando a esta se le hubiere dado muerte o estuviere desaparecida. De la misma forma, se consideran víctimas las personas que hayan sufrido un daño al intervenir para asistir a la víctima en peligro o para prevenir la victimización.

Esta es la forma como el Estado colombiano reconoce a las víctimas del conflicto armado pero desde este artículo se propone una mirada y el nombrar de las víctimas como ese ser que se autoreconoce como un sujeto de derechos que le han sido vulnerados violentamente y por lo tanto su voz se visibiliza como forma de resistencia. Porque una víctima no solo da razón de las secuelas de la guerra en su territorio, en su cuerpo, en su familia o comunidad, sino que además se sabe en la omisión o "ausencia" de las políticas sociales.

Entonces para el trabajo social existe una apuesta ético-política al nombrar las víctimas. ¿Cómo nombrarlas de tal manera que haya una eficacia simbólica contenida en la discursividad, en la gramática, en la retórica de lo social para señalar el horizonte de la intervención? Los sujetos -en este caso las víctimas del conflicto armado- no pueden ser definidos ni nombrados únicamente desde el universo de la victimización por el conflicto armado, sino de las diferentes formas que la exclusión social que han asumido incluso antes de los sucesos ocurridos, ya sea por la edad, el sexo, la raza, el estrato socioeconómico o cualquier otro significante como por ejemplo, qué grupo al margen de la ley cometió el hecho victimizante y cuál fue este, los procesos de mediación, la discriminación, los retos de acceso al mercado laboral, la vida urbana en la que a muchos les toca inmiscuirse luego de lo acontecido, los procesos de desarrollo comunitario, la participación efectiva, etc. (Matus, 2003). Para ello Nora Aquín (2006) propone la intervención social como un espacio de luchas en el que al cambiar las palabras ya se pueden cambiar las cosas; y en el que para conocer científicamente se comienza por una lucha contra las palabras.

Luego entonces, una de las reflexiones que podría darse desde este escenario de intervención sobre las víctimas es que es un ser humano que a pesar de la exclusión y el hecho perpetrador puede seguir en pie con la esperanza de recuperar lo que intentaron quitarle: la dignidad de ser humano. Sujeto de derechos porque sus derechos siempre estuvieron legal y legítimamente reconocidos y establecidos en la Constitución Política de este país, aunque el modelo se haya encargado de hacerlos invisibles.

Además de lo mencionado, la categoría de víctimas no es universal. Nombrar y comprender a las víctimas pasa por un tema de género, generacional, una perspectiva de interculturalidad, un enfoque diferenciado, étnico-racial. 
La comprensión de las mismas debe pasar por la interseccionalidad de una categoría con otra. No es lo mismo una mujer heterosexual víctima de abuso sexual que una mujer lesbiana víctima del mismo abuso, por ejemplo; así como tampoco es igual el mensaje que se pretende transmitir a través de la victimización. No son iguales las víctimas indígenas Zenú que las víctimas de Palenque, aunque uno solo sea el departamento de Bolívar. No es lo mismo una víctima campesina que una sindicalista, y mucho menos si una es una víctima negra y la otra persona es mestiza.

Nancy Fracer por su parte, ha señalado que para aplicar el enfoque diferencial hay que ubicarse en las discusiones sobre igualdad y diferencia, y en la pretensión de combinar las luchas por el reconocimiento y las luchas por la distribución (Citado en Montealegre 2010). Es decir, el debate no debe sólo centrarse en la discusión sobre cómo construir identidades individuales y colectivas, sino que además debe tener en cuenta el medio en el cual se da lugar a estas construcciones (contextos de inequidades y de conflictos políticos, sociales y particularmente en este caso, el contexto del conflicto armado). Se tratará entonces, a partir de este enfoque, de tener herramientas políticas y de derechos humanos que busquen el reconocimiento de las diferencias y transformar esas inequidades existentes a partir de la inclusión de las voces y actores que las representan.

Por otro lado, las Naciones Unidas de Derechos Humanos a través del Alto Comisionado en Colombia (2013) ha manifestado que dicho enfoque tiene un doble significado: es un método de análisis y al mismo tiempo, una guía para la acción. "En el primer caso, emplea una lectura de la realidad que pretende hacer visibles las formas de discriminación contra aquellos grupos o pobladores considerados diferentes por una mayoría o por un grupo hegemónico. En el segundo caso, toma en cuenta dicho análisis para brindar adecuada atención y protección de los derechos de la población" (p.13).

Es decir, en el caso del conflicto armado el enfoque diferencial ha de permitir la comprensión de las poblaciones que por sus características particulares, en razón de su edad, género, orientación sexual, grupo étnico y situación de discapacidad, requieren una intervención social diferenciada en cuanto a ayuda humanitaria, atención, asistencia y reparación integral e incluso, participación. Sin embargo, en el conflicto armado se agudiza la discriminación puesto que se cruzan y entran en intersección varias categorías en una sola: la de víctima. La identidad de clase, relacionada con el género y la raza, en una muestra como esta: "A veces pienso que fue por mandado de Dios o prueba que Dios le da a uno... también creo que me pasó por el hecho de ser pobre, negra y mujer" (Citado en la Comisión de Verdad y Memoria de Mujeres Colombianas, 2013, p.477), reafirma que dicha interseccionalidad configura situaciones de No. 15. Agosto de 2015 Palobra 
extrema vulneración y rechazo social, que el trabajo social en este campo no puede pasar inadvertido.

No obstante, a pesar de las diversas identidades y categorías que convergen en una sola: "víctimas", no se puede perder el verdadero sentido de la intervención con éstas y es que son sujetos de derechos. Nombrarlas primeramente de esta manera y no de otra, hace parte del rol ético-político asumido, puesto que las personas que demandan la intervención son ciudadanas a quienes se les ha vulnerado como mínimo un derecho. No es un necesitado, porque no necesita, viene a reclamar lo que violentamente le han quitado. No es un usuario, porque usuario es quien usa algo y si no lo tiene no lo puede usar. Tampoco es un beneficiario de una política pública que aparece gracias a la Ley 1448, porque un beneficiario se beneficia de algo, y ¿qué beneficio puede tener a quien le toca pedir o reclamar? (Dell'Aglio, 2013).

Bien diría Raquel Gentile en 1998 que "la importante tarea política realizada por la profesión, en su ámbito de trabajo, se refiere a las cuestiones de ciudadanía en sus dimensiones civil, económica, social y política (...) El servicio social no es solo una profesión viable políticamente, sino, sobre todo, puede contribuir efectivamente a la construcción de un mundo nuevo, libre de opresiones, injusticias, autoritarismos y desigualdades de todo orden" (Citado en Dell'Aglio, 2011, p.64). De allí la importancia del rol ético-político ya planteado con anterioridad.

\section{Intervención de trabajo social en el contexto del conflicto armado}

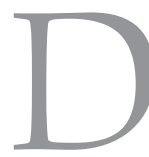
ebe ser asumida la intervención como una acción social transformadora, consciente y deliberada, en la que confluyan apuestas ideológicas, políticas -en este caso, con el fin de generar incidencia política-, filosóficas con procedimientos metodológicos en fundamentaciones que la puedan sustentar. Supone un camino que empieza con el conocimiento de las problemáticas (el conflicto armado, el contexto, causas, lógicas de este, consecuencias, etc.): se identifican actores (Estado, instituciones, organizaciones, víctimas colectivas e individuales, etc.), situaciones y circunstancias a evitar y a mejorar; se reconocen diferentes realidades que subjetivamente se han construido mediante representaciones y la comprensión interna de los hechos; se apoya en teorías sociales que juegan un papel de guía en el conocimiento, procesos y resultados (Cifuentes, 2004).

Luego entonces, en la búsqueda de ese trabajo social cuya intervención con las víctimas del conflicto sea como la mencionada, se ha intentado un análisis 
más profundo, no solo desde el absolutismo economicista sino también desde una mirada más sociológica y holística en la reparación integral, procurando la comprensión de aquellos cambios que no fueron deseados por las víctimas del conflicto armado, de sus entornos, las relaciones y los bienes (materiales e inmateriales) que amaban y les fueron arrebatados con violencia. Este trabajo social, desde lo simbólico, implica una reparación de la humillación, del despojo, de los proyectos que no pudieron realizar, del olvido estatal. Una reparación del enojo, de las iras, de la impotencia experimentada, del sufrimiento y la culpa (Grupo Nacional de Memoria Histórica, 2013). Es una reparación para la verdad y la no repetición de estos hechos.

El conflicto armado en Colombia también ha dado un rumbo, sin lugar a dudas, a las prácticas de los y las trabajadoras sociales, pero de manera especial en los microcontextos como el de Bolívar en el que Estado ha tenido poca presencia efectiva y visibilidad en el territorio, sobre todo en las zonas de mayor intensidad del conflicto como el sur de Bolívar y los Montes de María. Aunque como lo diría Alayón, los Estados nunca han estado "ausentes", ya sea por presencia o por "ausencia", los Estados siempre están presentes, pues detrás de cada omisión seguramente hay una intención políticamente pensada (Alayón, 2010).

Una de las dificultades más relevantes a la hora del quehacer profesional en este contexto es señalada por Martha Nubia Bello al iniciar a principios de este siglo, cuando menciona que "los y las estudiantes, a pesar de su formación académica, se tropezaron con un país desconocido que nunca figuró en los libros de historia, se encontraron con culturas extrañas y situaciones que desde los informes de gobierno y medios de comunicación parecían superadas. Las metodologías de trabajo aprendidas desde las diversas profesiones, caracterizadas por argumentaciones lógicas y coherentes se tropezaron con realidades que las hicieron inaplicables (...)" (Citado en Duque, Patiño \& Ríos, 2007 , p.10). Es decir, la complejidad de este escenario de conflicto armado en el país y mucho menos en Bolívar, nos es revelada solo hasta el momento de la intervención, hasta el momento del conocer ¿qué pasó? ¿cómo pasó? ¿qué puede pasar?, ¿qué se quiere que pase? y ¿cómo quiere que pase?

También se hace menester destacar que este proceso de intervención social, se ha construido en tensiones y contradicciones cotidianas que dificultan la reparación integral -aún más la simbólica- entre las cuales se pueden destacar las siguientes: 
- Las demandas de las comunidades suelen ser con inmediatez y las respuestas por parte de la institucionalidad son lentas y paquidérmicas debido a la tramitología burocrática propia de estas. Por ejemplo, una comunidad para acceder a una conmemoración por parte del gobierno departamental en Bolívar, debe presentar un proyecto a la Secretaría para las Víctimas y DDHH -que debe ser elaborado con una metodología específica y que las comunidades rurales muchas veces no están capacitadas para hacerlo- , esta lo envía a la Secretaría de Planeación para las correcciones -que suelen ser muchas, debido al desconocimiento del contexto y de las complejas realidades de las víctimas en el departamento por parte de muchos funcionarios-, luego pasa a una aprobación financiera y al final, queda a expensas de los intereses del gobernante de turno.

- Los territorios viven bajo la amenaza y el riesgo de un conflicto armado que no se ha detenido sino transformado, luego entonces se construyen intervenciones transformadoras en medio de la impunidad, la injusticia y entre la zozobra y la inseguridad (amenazas constantes a líderes, riesgos de desplazamiento, el narcotráfico en algunas zonas, las bandas criminales, etc.). Es de público conocimiento las amenazas a los líderes de El Carmen de Bolívar, de la comunidad de ASOCAB, por ejemplo. En varias ocasiones al llegar al territorio se tuvieron hostigamientos por parte de grupos ilegales, no se pudo tomar ninguna información o concretar reuniones. Es una tensión con la que conviven aún, muchas víctimas del conflicto armado en Bolívar.

- Se llevan a cabo muchos proyectos inspirados en las nociones de "desarrollo y modernización" que no corresponden a las lógicas y cosmovisiones de las comunidades. En la comunidad palenquera de La Bonga, por ejemplo, se han realizado diferentes proyectos, como el denominado Palenque 2015 a través del cual han construido casas, han llevado el servicio público del gas, entre otras apuestas, pero las personas víctimas del desplazamiento colectivo manifiestan que aunque estos hechos buscan elevar la calidad de vida en Palenque (corregimiento del municipio de Mahates), se está perdiendo la cultura agrícola que corresponde a la forma tradicional de ejercer actividades económicas dentro y fuera del territorio, han cambiado muchas de sus manifestaciones culturales como los juegos, la comida, la música, la medicina ancestral, etc., que para ellos constituye una cosmovisión del desarrollo y patrimonio importante de su pueblo. 
- Los liderazgos y los procesos comunitarios suelen institucionalizarse y formalizarse, causando consecuencias negativas sobre la autonomía y de la identidad comunitaria y política de los mismos. Liderazgos que llegan a ser viciados por sus intereses particulares y ya no representan comunidades.

- El acostumbramiento al asistencialismo por parte de algunas víctimas como consecuencias de la tradicional intervención social con víctimas que han sido puntualizadas en entregas de cosas. Esto puede crear una idea errada sobre la reparación, relacionándola solo con económico y por tanto, darle poco valor a la reparación en su dimensión simbólica.

\section{¿Qué dice la ley? ¿Cómo se operacionaliza en Bolívar?}

hora bien, la ley 1448 del 2011 es el referente normativo que tiene
esta práctica profesional, en ella se dictan las medidas de atención,
asistencia y reparación integral a las víctimas del conflicto armado interno. Siendo esta ley la que sienta las bases de una política pública bajo los principios de progresividad, gradualidad y sostenibilidad.

De esta manera, reza la ley sobre la reparación integral en su artículo 25 lo siguiente: "las víctimas tienen derecho a ser reparadas de manera adecuada, diferenciada, transformadora y efectiva por el daño que han sufrido como consecuencia de las violaciones de que trata el artículo $3^{\circ}$ de la presente Ley. La reparación comprende las medidas de restitución, indemnización, rehabilitación, satisfacción y garantías de no repetición, en sus dimensiones individual, colectiva, material, moral y simbólica. Cada una de estas medidas será implementada a favor de la víctima dependiendo de la vulneración en sus derechos y las características del hecho victimizante" (Ley 1448, 2011). Así, la Unidad para la Atención y Reparación Integral a Víctimas, ha enseñado que tanto la asistencia como la reparación tiene unas medidas propias.

Por otro lado, comprender que el conflicto armado en Colombia ha dado un orden a las distintas esferas del país (política, cultural, social y económica), generando unas consecuencias profundas que recaen sobre las víctimas (en sus individualidades y colectividades) y en la sociedad colombiana en general, ha construido unas subjetividades y realidades sociales que dan lugar a las prácticas sociales, las cuales adquieren unas dinámicas propias y pasan a formar parte de las características del ámbito social y comunitario en el cual se inscribe el quehacer del trabajo social (Bello, 2005). 


\section{Asistencia}

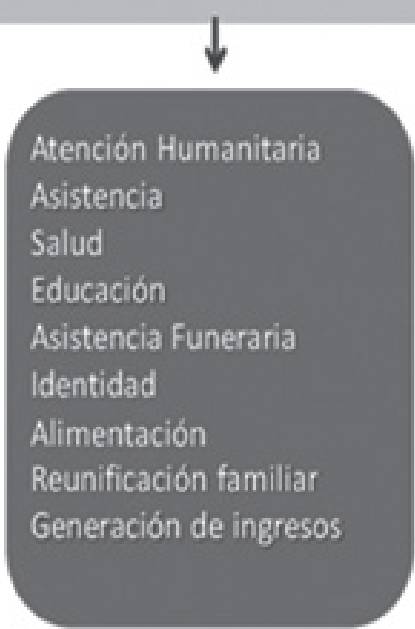

\section{Reparación}

Restitución

Rehabilitación

Indemnización

Medidas de satisfacción

Garantias de no repetición
Colectiva

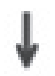

Planes de

Reparación

Colectiva

(comunidades y

grupos étnicos)

Fuente: UARIV, 2013

La Ley de Víctimas y Restitución de Tierras impuso obligaciones a los municipios y departamentos, una de ellas es formular planes integrales de atención y reparación a las víctimas que, en cuanto a nuestro departamento, a través del Plan de Desarrollo "Bolívar Ganador", el programa de atención y reparación integral a víctimas del conflicto en el territorio se operacionaliza a través de varios subprogramas:

- Atención y reparación integral a víctimas y restitución de tierras.

- Fortalecimiento a instancias de coordinación y participación (Comité de Justicia Transicional y Mesa Departamental de víctimas).

- Creación de la Secretaría de Víctimas y Derechos Humanos -donde se gestó la experiencia aquí nombrada-.

- Construcción de los centros regionales de atención a víctimas.

- Plan Integral Único de atención a población en situación en desplazamiento. Este plan se constituyó en el primer ejercicio realizado en el departamento en materia de diseño de iniciativas gubernamentales con carácter de política pública dirigido a víctimas en 2011. 
Para el periodo 2012-2015, Bolívar construye un Plan de Atención Territorial -PAT-, el cual realizó primeramente una caracterización de las víctimas en el departamento, luego una planeación estratégica de la política pública para este tiempo y al final, la gestión, seguimiento y evaluación de dicha política.

La política pública en Bolívar es una territorialización de la ley en el departamento. Por ello contempla los componentes establecidos en ella: prevención y protección, atención integral, reparación integral, participación efectiva y fortalecimiento institucional.

\section{¿Y la intervención del trabajo social en este contexto?}

omprender que el conflicto armado en Colombia ha dado un orden a las distintas esferas del país (política, cultural, social y económica), generando unas consecuencias profundas que recaen sobre las víctimas (en sus individualidades y colectividades) y en la sociedad colombiana en general, ha construido unas subjetividades y realidades sociales que dan lugar a las prácticas sociales, las cuales adquieren unas dinámicas propias y pasan a formar parte de las características del ámbito social y comunitario en el cual se inscribe el quehacer del trabajo social (Bello, 2005).

Entonces surgen las siguientes preguntas: ¿Cuál es el papel del trabajo social en medio de la búsqueda por reparar de manera integral a las más de seis millones de víctimas que existen en el país?, ¿cuál es la intervención a realizar en este contexto?, ¿cuáles son los desafíos?, ¿dónde empieza la acción social reparadora?, ¿qué hacer con la asistencia y qué papel juega en la reparación?, ¿qué apuesta tener frente a las víctimas con necesidades puntuales?

Se hace menester pensar en la asistencia, porque además de ser una medida para la reparación integral, ha sido un papel preponderante en la historia de la profesión y de manera especial, en este contexto. Y si bien no es lo mismo que el asistencialismo, no se debe hacer un rechazo de la asistencia solo porque teorizamos sobre las realidades sociales ajenas desde el frío de las oficinas. Las víctimas del conflicto armado, algunas ya sin ganas de nada, otras con una pequeña esperanza y otros con grandes sueños, aún por encima de la intencionalidad de quienes ejecutan y diseñan las prácticas asistencialistas o asistenciales, reciben lo que se les brinden para paliar sus carencias más puntuales; y el trabajo social no puede estar con una visión a medias para comprender la enorme dimensión que adquiere una asistencia para quien la recibe. Las necesidades concretas pueden convertirse en un punto de partida; y a partir de ello se puede impulsar formas organizativas y procesos de lucha por la reivindicación. ¿Qué víctima después de la humillación de quedar sin 
tierras, sin trabajo, sin algún familiar, sin amigos cercanos, enferma o con hambre estará en condiciones de impulsar procesos de reivindicación, lucha y resistencia? Claro está que, no se puede discutir que al interior de los grupos dominantes se gestan intenciones de desmovilizar, detener, señalar negativamente y amortiguar el nivel de reivindicación de las personas que históricamente en su mayoría han sido excluidas, como las víctimas del conflicto armado.

Dentro de esta práctica reflexiva se ha observado que no han sido las donaciones en sí mismas las que han frenado procesos reivindicadores. Las conquistas sociales, por lo menos en el departamento de Bolívar, se han visto frenadas ante la fuerza de la represión y nada más; ejemplo de esto son las comunidades de Las Palmas en San Jacinto quienes han resistido la violencia estructural, el conflicto armado y al rezago estatal y han conquistado procesos de reivindicaciones, nuevas organizaciones comunitarias, pero a la voz de represión de cualquier actor, suelen entregar ganancias que se han adjudicado; la comunidad de Las Pavas en el Sur de Bolívar es otro ejemplo de resistencia pacífica en la lucha por el derecho a la tierra, el trabajo, pero una vez que un grupo político junto a uno al margen de la ley intenta reprimir sus voces, ellos ceden. Sin embargo, luego de la incidencia de muchas instituciones, la resistencia, la capacidad organizativa de las comunidades, la asistencia se convierte en un elemento pero no en el fin. Lo que no sucede con comunidades sin procesos de reivindicación fuertes.

Bien mencionaba Norberto Alayón que "los trabajadores sociales tendremos que demostrar agudeza y capacidad para operar idóneamente ante la dialéctica existente entre la concesión de reivindicaciones por parte de los grupos dominantes y la conquista de reivindicaciones por parte de los grupos dominados" (1980, p. 10); de ahí que no sea difícil escuchar expresiones como "no queremos que nos den nada, solo queremos poder trabajar en nuestras tierras", "son nuestros derechos, no son un favor" o cosas parecidas. Por razones como estas ha de considerarse importante la indemnización vía administrativa como derecho de las víctimas y ha de presentárseles a estas como tal, pero no como el fin de la reparación.

Por lo tanto, la intervención social en la reparación de las víctimas del conflicto armado no puede ser vista como una forma de operacionalizar la ley 1448 y la política pública que despliega, sino que en el ejercicio profesional se puede gestionar un espacio público puntual. Del mismo modo, la potencia 
que tienen las intervenciones sociales es la posibilidad de construir y ampliar el espectro en cuanto a lo público, en cuando a la exigibilidad de derechos, aunque para ello acuda a la asistencia en algunas instancias, pero no se agota allí (Matus, 2003).

Al mismo tiempo, la apuesta por la reparación de las víctimas, pasa también por generar reflexiones desde y para las instituciones, sus representantes, sus funcionarios (públicos o no), quienes cotidianamente son el rostro visible de la política pública. La insensibilidad, el prejuicio, la estigmatización, la indiferencia y hasta la barbarie, suelen asomarse en dichos rostros.

La cuestión es que la víctima adopta las características dadas por quien la mira, la nombra, por quien trabaja con esta población; y si bien a esa víctima en su mayoría excluida, vulnerada, subordinada, jerarquizada, se le puede conceder alguna virtud estética o moral, si no hay una sensibilización introyectada, muy difícilmente se le va a otorgar el estatuto de legítimo pensamiento; a la víctima muy difícilmente se le comprenderá como sujeto de derecho y no objeto de favores. Se hace urgente que el trabajo social posibilite y proponga nuevas narrativas que permitan la profundización en los vínculos de pertenencia, de participación y de reconocimiento, tanto con las instituciones y quienes las representan como con las víctimas. Ya menciona Matus de manera muy acertada que, "se requiere enunciar que el núcleo de toda intervención es la potenciación de sus sujetos. Una agenda social sin sujetos es una agenda vacía" (2003, p. 61).

Por otro lado, no podría dejar de lado en la intervención con víctimas del conflicto armado desde el trabajo social la relación directa que se tiene con el drama humano y las consecuencias emocionales en quien realiza la labor profesional. Ser testigos de las consecuencias devastadoras del conflicto no es una tarea fácil y no pasa por encima de las personas que optan por la esperanza a través de su trabajo, mencionando además que en este escenario, es probable que algunos profesionales sean víctimas directas de la violencia, amenazados, hostigados y perseguidos por grupos al margen de la ley. No mencionarlo restringe la mirada crítica sobre cómo las posturas íntimas (creencias, miedos, prejuicios y emociones) y profesionales (ética, política, epistemológica, metodológica) son potencialidades u obstáculos para el objeto de la intervención (la reparación integral). Los papeles que se adopten (mesiánico, heroico, crítico-reflexivo, propositivo, de acompañamiento) dependen en gran parte de la situación emocional de quienes apoyan los 
procesos de reparación (Corporación Vínculos, 2009).

Por último en este aparte, se considerarán algunas recomendaciones sobre el trabajo social para la reparación integral a víctimas:

- El contexto de conflicto armado y violencia en Colombia debe configurarse en un referente fundamental para el accionar, para la investigación y para la producción del trabajo social contemporáneo en la realidad del país y sus departamentos.

- Trabajar en equipos intersectoriales e interinstitucionales, en donde se arriesgue más allá de las funciones y conocimientos de base, para configurar campos de comprensión y acciones interdisciplinares, intersectoriales e interinstitucionales a partir del diseño de agendas participativas (Estrada, Ripoll \& Rodríguez, 2010).

- Es necesario que desde la academia -en especial, desde la Universidad de Cartagena- se empiece a gestar mayor reconocimiento al conflicto interno como una realidad que atañe a las ciencias sociales y pide un espacio dentro de los currículos que permitan la participación de los y las estudiantes en la investigación (nuevos grupos respecto al tema), la comprensión y la producción de conocimiento alrededor de la realidad del conflicto y sus implicaciones.

- El cómo, lo metodológico es siempre producto de la creatividad, del enfoque del trabajo social, de la apuesta ética y política y de las actitudes de cada profesional; realizar los quehaceres profesionales en este escenario cuando la formación profesional en el tema fue incipiente, genera incertidumbres, pero allí se encuentra el reto de actualizarse, de mantener la atención a las nuevas exigencias del contexto, de arrancar un proceso auto-formativo, entendiendo desde la experiencia que la academia representa tan solo una pequeña parte en la construcción de conocimiento, la cual empieza realmente con el enfrentamiento a la realidad que supone la práctica académica o profesional. Es en interacción con los procesos sociales como consolidamos tanto nuestra formación como nuestra identidad profesional (Estrada et al., 2010).

\section{El arte como herramienta de intervención social}

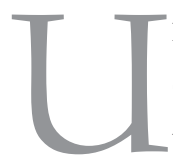

- na canción de Teresa Parodi (2002), cantada en una especie de coro entre lágrimas, en el marco del encuentro de la Comisión de Verdad -y Memoria de Mujeres Colombianas, luego de que estas contaran sus dolores y sus luchas en el conflicto armado, fue una especie de llamado 
a darle importancia a las medidas de satisfacción en esta intervención social. Estas mujeres entonaban el tema "Resistiendo", del cual vale la pena rescatar un fragmento: "En la subasta se llevaron todo, enajenando nuestro corazón, se repartieron hasta lo imposible pero no pueden con nuestra canción". Luego se mantenía repitiendo una y otra vez el coro: "nos han robado hasta la primavera, pero no pueden con nuestra canción, parece frágil pero no se entrega, sigue cantando como vos y yo". A partir de eso, sin duda alguna, debía replantearse el poder otorgado a la reparación en su dimensión simbólica como una forma de intervención profesional.

Luego entonces, reflexionando sobre el papel del trabajo social en esta dimensión simbólica, ha de comprenderse que no se pretende recaer sobre lo perdido sino sobre lo que esto representaba para las víctimas. Lo que en la canción de Parodi, sería el significado de las primaveras para las personas y no las primaveras en sí mismas. Y siguiendo con el ejemplo, aunque se repartieron hasta lo imposible, la indemnización vía administrativa intentará restituirlo de la mejor manera y la reparación simbólica surgirá por la necesidad de reclamar justicia, significando el reconocimiento del daño sufrido y la ruptura del dolor con que se ha vivido la pérdida, porque no pueden con nuestra canción.

La reparación integral está constituida por la reparación simbólica porque su significación está sometida a la subjetividad de las víctimas. Es decir, son ellas mismas quienes establecen la relación entre lo que el Estado a través de la reparación ofrece y lo que se ha perdido. Las medidas de satisfacción son hechas al molde de las víctimas porque está estrechamente ligado a las características personales, el contexto y las creencias de las víctimas. Cada persona o comunidad tiene un mundo referencial, marcado por sus culturas, etnias, sexo y edades, entre otros, que le dan el repertorio de sentidos para interpretar su realidad y los hechos más importantes desde su propia óptica (Guilis, 2004). Es allí donde el trabajo social juega un papel muy importante en la comprensión de dichas subjetividades y en el nombramiento de ellas. Por ejemplo, la población palenquera -Mahates, Bolívar- que fue desplazada de la vereda de La Bonga ha percibido preponderante el papel de la agricultura como vía para la reparación de su pueblo, y es entendible, cuando esta zona antes del desplazamiento colectivo era una fuente de abastecimiento incluso para la ciudad de Cartagena, en palabras de una mujer de la comunidad "no éramos ricos, pero lo teníamos todo"; luego entonces, su reparación simbólica ha de tejerse alrededor de este contexto histórico. Pero en el caso de pueblos indígenas otras serían las interpretaciones dadas a la pérdida y al potencial de la reparación simbólica. He allí el carácter subjetivo que se mencionaba, del cual Castoradis afirma que: "Para la visión 'procedimental', los humanos (o 
una parte suficiente de ellos) deberían ser puro entendimiento jurídico. Pero los individuos afectivos son otra cosa muy distinta. Y uno está obligado a tomarlos tal como vienen, ya moldeados por la sociedad, con sus historias, sus pasiones, sus pertenencias particulares de todo tipo; tal como los fabricó el proceso histórico-social y la institución dada de la sociedad" (Castoradis, 1997, p. 289).

Ahora bien, esta experiencia resalta la dimensión de lo simbólico como parte de la reparación integral a las víctimas del conflicto armado y como una propuesta para tener en cuenta desde el quehacer profesional; tal como se mencionó, está implicada en la ley a través de las medidas de satisfacción en las que se hace búsqueda de la verdad, se recopila información, se construye la memoria histórica y se divulga; se conmemoran los hechos y días de remembranzas. Sobre el cómo hacerlo, se tiene la respuesta: a través del arte.

En una de las entrevistas conversacionales realizadas en esta experiencia, César López, músico conocido por la creación de la escopetarra y otras apuestas por la paz del país, hacía mención del arte como aquella herramienta que permite saber qué pasó a la sociedad, pero también le habla a las instituciones para comprender lo sucedido, para interpelar. El arte ha ayudado a las víctimas del conflicto armado a representarse y a reconstruir sus identidades, y por supuesto a exponer su dolor, para saber qué pasó, cómo pasó, quién lo hizo y así construir garantías de no repetición. Y como si fuera poco, el arte sensibiliza y mientras haya personas sensibles, humanos y humanizados, se tendrá una generación más compasiva y más solidaria. No resuelve problemas estructurales, pero permite ser un puente, permite tramitar, permite denunciar, permite soñar.

Por ello, es tan fácil darse cuenta al llegar a la comunidad de campesinos en Las Pavas -hacienda en el municipio El Peñón- que, sus niños conocen la historia de conformación del pueblo, desplazamiento, y resistencia gracias a las canciones que los paveros han ido creando. Por ejemplo, con respecto al hostigamiento suelen cantar con frecuencia: "el enemigo que ataca que no duerme noche y día, ahora quemaron la casa donde Norita dormía", o respecto a su identidad: "campesino, campesino de verdad, orgullosamente yo soy un buen pavero, porque es aquí donde tengo la oportunidad de hacer canciones y cantarle a mi pueblo"; y así, infinidades de canciones, que en paralelo a los dibujos a mano alzada realizados por Rafael Posso en Las Brisas, San Juan Nepomuceno, contando la masacre de los suyos, las mujeres tejedoras de Mampuján y la historia de la colonia a través de telas; permiten transmitir 
sus historias de vida, soñar, denunciar, humanizar.

Diría el dramaturgo Tony Kusher que, el arte no es una simple contemplación, es a su vez un acto y los actos cambian el mundo. Aunque el arte haya sido utilizado como instrumento por las élites, no es un transmisor obediente de información, sino que realiza todo lo contrario, deja en evidencia las relaciones de poder y desequilibrio que se imponen desde el sistema colombiano. El arte es una alternativa de intervención social donde su fin no es en torno a la belleza sino a lo terapéutico, la formación y educación, que sirve para la recuperación de la memoria y desarrollo de creativas formas de resolución de conflictos (Citado en Pascual, 2004).

¿Por qué permitir el arte en la construcción de memoria histórica?, ¿para qué facilitar una canción, una obra de teatro, una máscara, un cuento, un poema, una expresión artística y/o videográfica? Para dar validez a las voces de las víctimas, para reconocer sus expresiones como válidas y con estatus político, como un asunto que constituye el trabajo social para las transformaciones. "El arte es una solución. Es el signo de la cultura y la cultura es lo que da consuelo frente a la certeza del caos y a la contundencia del horror que viene ocurriendo desde hace muchísimo tiempo. La cultura es un analgésico, no un anestésico. La cultura es lo que da serenidad frente al desastre" (Citado en Cervantes, 2014, p.3), afirmaría el periodista español Arturo Pérez-Reverte.

Las víctimas del conflicto armado hacen uso de herramientas de su cotidianidad, de sus creencias, de sus manifestaciones artísticas (canciones, dibujos, historietas, telares, etc.), de sus valores ancestrales para contar sus propias verdades, las historias de la historia. Entonces nuevamente vuelve a interrogarse sobre el papel del trabajo social en la construcción de memoria histórica, por ejemplo.

La respuesta desde esta reflexión insta de cuatro asuntos: por un lado, propiciar estos espacios que permitan la interacción de las víctimas y la construcción de sus iniciativas que incluso, generen unas redes entre diversos colectivos y comunidades. De otro lado, una interpretación que capture estas memorias que constituyen "una verdad esencial acerca de la [su] experiencia" (Stern, 2005 , p. 113). Tercero, ya que estas iniciativas de memoria histórica develan "alianzas de carácter político o militar, participación directa y material en los hechos, apoyo económico o político, instigación, encubrimientos estratégicos, consentimientos pasivos, ayudas bajo coerción o miedo, observadores pasivos e indiferencia" (GNMH, 2013, p.343), el desafío será la divulgación 
conjuntamente con los constructores de dichas iniciativas para coadyuvar en la anulación de la impunidad y no sólo la judicial sino la moral, el desconocimiento total. Y por último, ser mediadores de nuevas esperanzas, constructores de tiempos de mariposas y ruiseñores para quienes han leído con tanto poder las profecías de la destrucción y la hecatombe.

\section{BIBLIOGRAFÍA}

ALAYÓN, Norberto (1980). El asistencialismo en la política social y en el trabajo social. Revista Acción Crítica [en línea], $\mathrm{N}^{\circ}$ 7. Disponible en http://www.ts.ucr.ac.cr/binarios/accioncritica/ ac-cr-007-05.pdf

AGUAYO, Cecilia; LÓPEZ, Teresa \& QUIROZ, Teresa (2007). Ética y trabajo social en las voces de sus actores. Un estudio desde la práctica profesional [en línea]. Disponible en http://www. ts.ucr.ac.cr/binarios/libros/libros-000011.pdf [2014, 18 de mayo]

AQUÍ́N, Nora (2006). La relación sujeto-objeto en trabajo social: Una resignificación posible [en línea], $N^{\circ}$ 2. Disponible en http://dialnet.unirioja.es/servlet/autor?codigo $=1854669$

BELLO, Martha (2005). Trabajo social en contextos de violencia política. Revista del Departamento de Trabajo Social, Facultad de Ciencias Humanas, Universidad Nacional de Colombia [en línea]. $\mathrm{N}^{\circ}$ 7. Disponible en http://www.revistas.unal.edu.co/index.php/tsocial/article/view/8472

CIFUENTES, Rosa (2004, Octubre). Aportes para "leer" la intervención de trabajo social. Ponencia presentada en XVIII Seminario Latinoamericano de Escuelas de Trabajo Social. La cuestión social y la formación profesional en trabajo social en el contexto de las nuevas relaciones de poder y la diversidad latinoamericana, Costa Rica.

CONFORTI, Franco (2010) Comentando el libro "Transformación de conflictos" Pequeño manual de John Paul Lederach. Barcelona: Icaria.

CORPORACIÓN VÍNCULOS (2009). Acompañamiento psicosocial en contextos de violencia sociopolítica [en línea]. Bogotá. Disponible en: http://corporacionvinculos.org/libros/Psicosocial/ Psicosocial.html [2014, 15 de julio]

DANRHEDORF, Ralf (1993). El conflicto social moderno. Madrid: Modadori.

DELL'AGLIO, Marta (2011). Un modelo de intervención social en dos modelos de país ¿Qué hacemos los trabajadores sociales? Revista Debate Público, Reflexión de Trabajo Social [en línea], $\mathrm{N}^{\circ}$ 3. Disponible en http://trabajosocial.sociales.uba.ar/web_revista_3/pdf/19_dellaglio.pdf

DUQUE, Lina; PATIÑ̃, Andrea \& RÍOS, Yulieth (2007). Conflicto, violencia y convivencia social como área emergente para el trabajo social. Revista Eleuthera [en línea], $\mathrm{N}^{\circ} 1$. Disponible en http://eleuthera.ucaldas.edu.co/downloads/Revista1_8.pdf 
GNMH. iBASTA YA! Colombia: Memorias de guerra y dignidad. Bogotá: Imprenta Nacional, 2003.

GUILIS, Graciela (2004). La reparación: acto jurídico y simbólico. Revista San José [en línea], $\mathrm{N}^{\circ}$ 3. Disponible en http://iidh-jurisprudencia.ac.cr/bibliote/index.php?option=com docman\&task=doc_download\&gid $=1222 \&$ Itemid $=54$.

GURR, Ted (1970). Why Men Rebel. Princeton: Princeton University Press.

PALACIO, M.; VALENCiA, A. \& SÁNCHEZ, M. Los conflictos y las violencias recientes en Colombia: Un pasado y un presente para contar. Manizales: Centro Editorial Universidad de Caldas.

FRANCO, Saúl (2003). Momento y contexto de la violencia en Colombia. Revista Cubana Salud Pública [en línea], $\mathrm{N}^{\circ}$ 29. Disponible en http://pobrezaymarginalidadencordoba.bligoo.com.co/ media/users/22/1130447/files/306078/spu04103.pdf

MATUS, Teresa. (1990). Propuestas contemporáneas en trabajo social. Hacia una intervención polifónica [en línea]. Disponible en http://Www.fcp.uncu.edu.ar/upload/ APUNTESSOBREINTERVENCIONSOCIAL.pdf

NACIONES UNIDAS, 17 de septiembre del 2007, Declaración de las Naciones Unidas sobre los derechos de los pueblos indígenas. Disponible en http://www.un.org/esa/socdev/unpfii/ documents/DRIPS_es.pdf

SILVA, Germán (2008). La teoría del conflicto. Un marco teórico necesario. Revista Prolegómenos. Derechos y valores, Vol XI, núm. 22, julio-diciembre. 